\title{
ТИПОМОРФНЫЕ ОСОБЕННОСТИ КВАРЦА В ПОРОДАХ КРИСТАЛЛИЧЕСКОГО ФУНДАМЕНТА И БАЗАЛЬНЫХ ОТЛОЖЕНИИ ОСАДОЧНОГО ЧЕХЛА ЭСТОНИИ
}

Наиболее информативными с точки зрения происхождения вещественного состава слоя являются подошва осадочных толщ и самые нижние слои базальных отложений. Именно анализ их должен ответить на вопрос, является ли этот разрез непосредственным продолжением нижележащего, или представляет собой что-то качественно новое.

При сравнительном изучении минерального состава кристаллических и осадочных пород мы учитывали не только ассоциации минералов, но и типоморфные особенности типичных унаследованных от коры выветривания минералов - циркона и кварца. Как известно, в процессах переотложения и транспорта тяжелые минералы гораздо менее подвижны, чем легкие и поэтому не могут в достаточной мере отражать особенности удаленных источников сноса. Представительная информация об источниках сноса достигается комплексным изучением типоморфизма как тяжелых, так и легких минералов. Из последних самым устойчивым и широко распространенным является, несомненно, кварц, способный транспортироваться на значительные расстояния, что в свою очередь обусловливает большую вероятность смещения материала из разных источников (Кац, Симанович, 1974). Поэтому в целях выяснения источников исходного материала обломочных пород большое значение имеет разносторонное изучение типоморфизма кварца.

По типоморфизму кварца из изверженных, метаморфических и осадочных пород имеется множество публикаций, но комплексное систематическое и сравнительное исследование типоморфных разновидностей кварца основных генетических групп пород только начинается. Предложены генетические классификации пород по основным типоморфным признакам (Krynine, 1946; Blatt, Christie, 1963; Кац, Симанович, 1974; Симанович, 1978; и др.).

Сравнительное описание минерального состава главных типов пород фундамента и базальных отложений осадочного чехла приведено нами ранее (Конса, Вийдинг, 1983; Клейн, Конса, 1986). Выявлены также типоморфные особенности циркона пород кристаллического фундамента (Конса, 1986a), коры выветривания фундамента (Конса, 1986б) и базальных отложений осадочного чехла (Конса, 1987). В настоящей статье рассматриваются результаты изучения типоморфных особенностей кварца в изверженных и метаморфических породах кристаллического фундамента, включая кору выветривания, а также базальные слои осадочного чехла нашего региона. Из проб неизменных кристаллических пород кварц выделялся дроблением, а из сильно выветрелых и осадочных пород - отмучиванием и последующим ситованием (фракция $0,1-0,05$ мм). В каждом иммерсионном препарате изучали около 400 зерен, причем фиксировали форму, тип погасания и характер включений кварца. При характеристике формы использовали также резудьтаты. изучения их в шлифах (Кристаллический ..., 1983) 


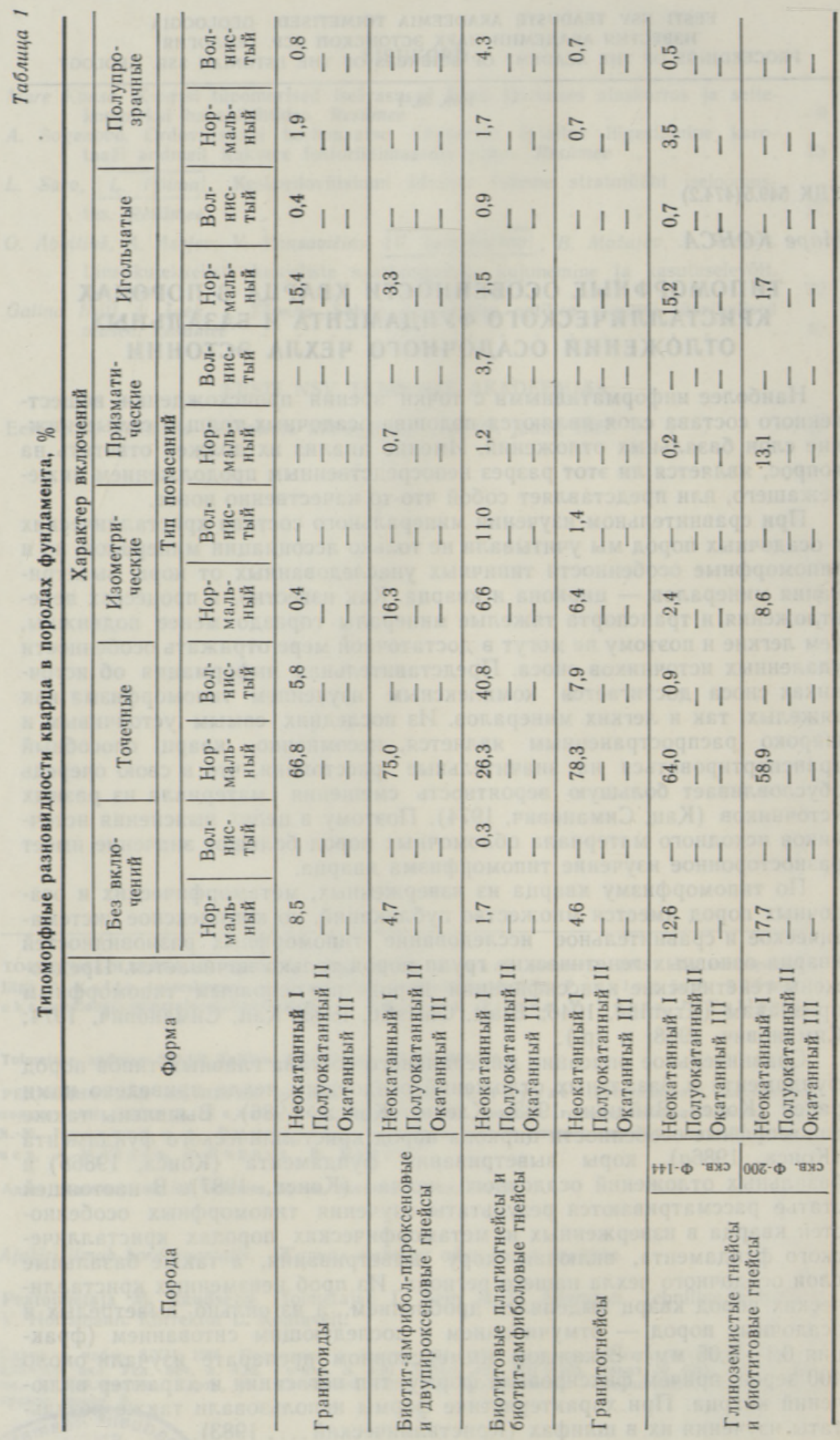


Ниже в сжатой форме изложены результаты изучения пород кристаллического фундамента по отдельным генетическим типам и разновозрастным литостратиграфическим подразделениям базальных отложений осадочного чехла Эстонии.

\section{Кварц в породах фундамента (табл. 1)}

1. Изверженные породы. Кварц изучен только из гранитоидов, наиболее широко распространенных в виде теневых гранитов и мигматитов в пределах Алутагузеской зоны. Он встречается в виде неправильных зерен, реже - мелких ксеноморфных скоплений с нормальным или волнистым погасанием. В рассматриваемых породах преобладает кварц с точечными включениями. По сравнению с метаморфическими породами наблюдается наиболее высокое содержание игольчатых включений (в среднем 16\% зерен). Сходная ассоциация включений характерна и для кварца рапакиви-гранитов (скв. Рухну). По данным литературы (Кац, Симанович, 1974), относительно высокое содержание игольчатых включений характерно именно изверженным породам.

2. Метаморфические породы. Кварц изучен из четырех более широко распространенных типов гнейсов.

В двупироксеновых и двупироксен-амфиболовых гнейсах кварц встречается весьма редко. Самостоятельные зерна появляются лишь в наиболее кислых разновидностях этих пород. В биотит-гиперстеновых гнейсах кварц встречается в качестве породообразующего минерала в виде мелких зерен, часто с волнистым погасанием. В изученном нами разрезе скв. Ф-164 образуются неправильные изометрические зерна с нормальным погасанием. По типу включений преобладают точечные, но встречается также много зерен кварца с изометрическими включениями. Реже попадаются зерна без включений и с игольчатыми включениями.

Биотит-амфиболовые гнейсы и биотитовые плагиогнейсы представлены обычно мигматизированными разновидностями, где кварц слагает в основном мелкозернистые мозаичные агрегаты или образует неправильные зерна с нормальным или волнистым погасанием. Преобладает кварц с точечными включениями. Существенную роль играет также кварц с изометрическими, реже с призматическими включениями, а также полупрозрачный кварц. Менее всего распространен кварц с игольчатыми включениями и без включений.

В гранито-гнейсах кварц образует неправильно-изометрические кристаллы с извилистыми очертаниями; погасание нормальное или волнистое. Преобладает кварц с точечными включениями, следует с изометрическими включениями или без включений. Другие разновидности кварца по включениям практически отсутствуют.

Глиноземистые и тесно переслаивающиеся с ними биотитовые гнейсы, как правило, повсеместно мигматизированы. Кварц в них образует неправильные зерна с извилистыми очертаниями, имеющие нормальное, реже волнистое погасание. Иногда кварц сильно гранулирован, образуя линзовидные выделения, состоящие из агрегата мелких зернышек. Состав включений кварца в глиноземистых гнейсах характеризуется большой изменчивостью. Преобладают точечные, следуют игольчатые включения, призматические встречаются изредка. Сильно варьирует количество кварца без включений.

Из вышеизложенного можно сделать следующие выводы.

Во-первых, кварц изверженных пород, в частности гранитоидов, характеризуется наибольшим количеством игольчатых включений (в среднем $16 \%$ зерен) и меньшим - изометрических и призматических.

Во-вторых, кварц метаморфических пород отличается разнообразием включений: точечных, изометрических и призматических, но почти пол- 
造

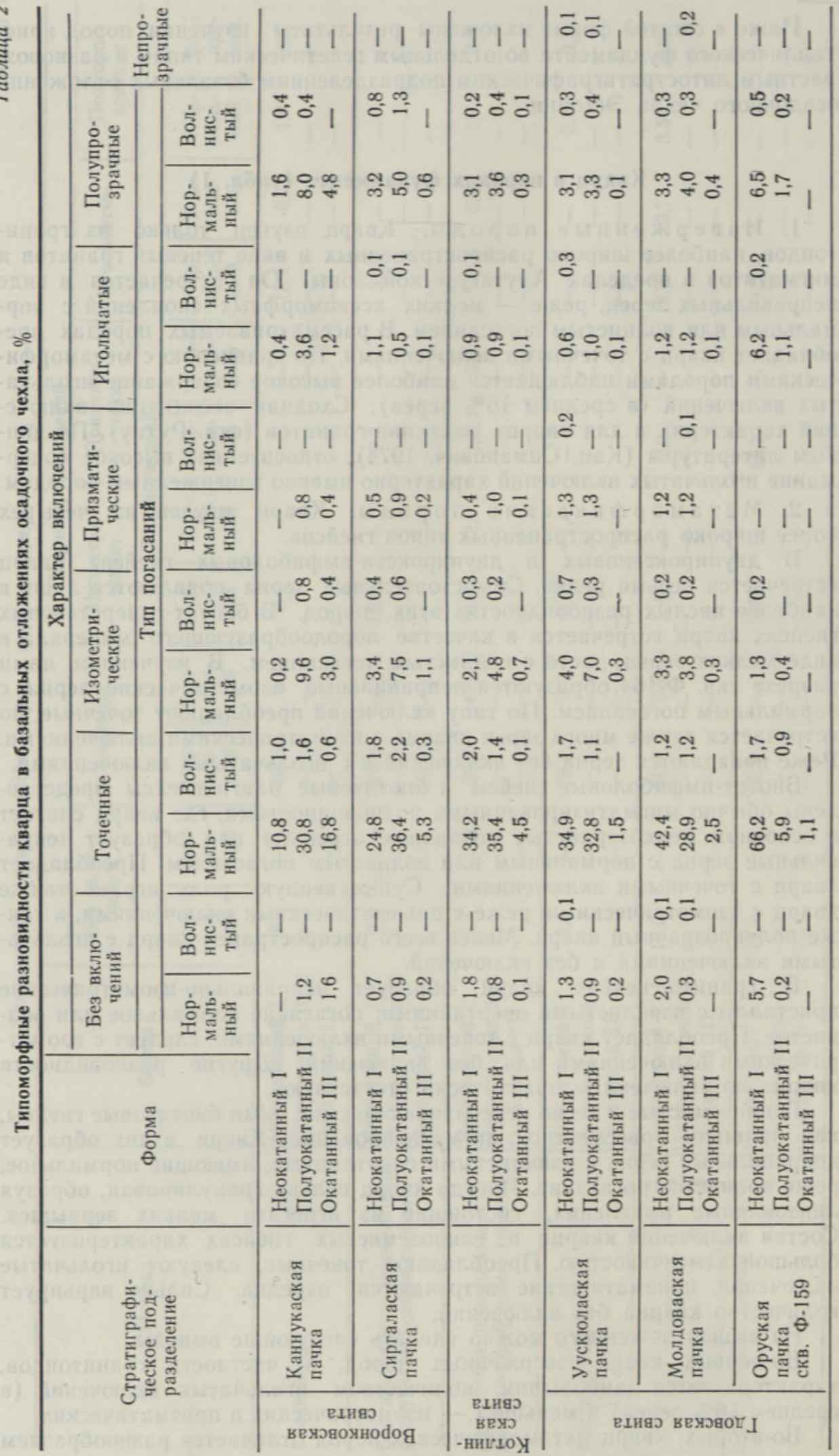


ным отсутствием игольчатых. Содержание последних не больше $4 \%$, обычно ниже $2 \%$. Если игольчатые включения в гнейсах встречаются часто и по составу они рутиловые, то порода претерпела гранитизацию (Симанович, 1978). Последнее, вероятно, объясняет повышенное содержание игольчатых включений в кварце мигматизированных глиноземистых гнейсов Алутагузеской зоны.

Таким образом, относительно высокое содержание игольчатых включений кварца следует считать индикаторным свойством изверженных, а также гранитизированных метаморфических пород. Остальные метаморфические породы характеризуются разнообразием точечных, изометрических и призматических включений.

\section{Кварц в коре выветривания}

Закономерности изменения горных пород по профилю коры выветривания на кристаллическом фундаменте охарактеризованы Т. Кууспалу и др. (1971), В. Ванамб и др. (1977). По интенсивности гипергенных изменений пород указанные авторы выделили четыре степени выветривания, обозначив их по мере нарастания изменений 0, I, II, III (Кристаллический ..., 1983).

При выветривании пород кристаллического фундамента под действием химических агентов кварц частично разрушался, корродировался, зерна обычно округлялись, становились полупрозрачными или непрозрачными. Степень округленности кварца закономерно возрастала при переходе от слабовыветрелых к сильновыветрелым разновидностям. В первую очередь разрушались зерна с многочисленными включениями. По данным Н. А. Лисицыной (1959), зерна кварца разъедаются глинистыми и железистыми минералами. Уже в нижней зоне гидрослюдистых глин они носят следы растворения, имеют изъеденные края, иногда замутненную поверхность и повышенную трещиноватость.

Местами кварц замещен гидроокислами железа, при их массовости образуются бобовиновидные обрастания вокруг ранее корродированных зерен.

В зоне выветривания II степени количество корродированных зерен увеличивается. Они часто становятся полупрозрачными или непрозрачными. В верхней зоне (III степень выветривания) каолинитовых глин количество измененных зерен увеличивается.

Однако наряду с измененными зернами в коре выветривания кристаллического фундамента встречаются нередко и свежие, очень малоизмененные зерна кварца.

Таким образом, характер кварца, поступавшего из кристаллического фундамента в базальные слои осадочного чехла, зависит как от состав пород (изверженные или метаморфические), так и от стадии их выветривания.

\section{Кварц в базальных слоях осадочного чехла (табл. 2)}

Как известно, разновозрастные отложения верхнего венда и нижнего кембрия залегают на выровненной поверхности остаточной коры выветривания фундамента (архей, нижний протерозой). Наиболее древние базальные отложения в Северо-Восточной Эстонии представлены оруской и молдоваской пачками гдовской свиты (Менс, Пиррус, 1980).

Разрезы оруской п а ки изучены по разнотипным породам фундамента. Типоморфные особенности кварца заметно различаются в зависимости от состава пород подстилающего слоя. 
Кварцы оруских отложений на коре выветривания чередующихся биотит-амфиболовых гнейсов и биотитовых плагиогнейсов нижнего протерозоя изучены по разрезу скважин Ф-159 (Вохнья), где породы кристаллического фундамента подвергались сильному выветриванию. Здесь резко преобладают неокатанные зерна $(89 \%)$, полуокатанных мало, хорошо окатанных - единичные экземпляры. Большинство зерен кварца имеет нормальное погасание, волнистое погасание наблюдается приблизительно у $5 \%$ зерен. Тип включений аналогичен таковым нижезалегающих гнейсов - преобладают точечные, встречаются изометрические и призматические. Часты кварцы без включений и полупрозрачные. В отличие от нижележащих гнейсов часто встречаются игольчатые включения. Можно предполагать, что отложения оруской пачки в данном месте сформировались в основном за счет коры выветривания местных, более или менее мигматизированных гнейсов.

Кварц изучен по керну многочисленных скважин непосредственно над глиноземистыми и биотитовыми гнейсами в пределах Алутагузеской структурной зоны. В этом регионе оруским отложениям характерно относительно большое разнообразие кварца. Резко преобладают неокатанные $(15-80 \%)$ или полуокатанные $(12-80 \%)$ зерна, количество хорошо окатанных колеблется от 2 до $10 \%$. В основном они имеют нормальное погасание; зерен с волнистым погасанием встречается в среднем $20 \%$. Наиболее распространен кварц с точечными включениями (60$85 \%)$, меньше - с изометрическими $(0,5-18 \%)$, призматическими $(0,5-5,0 \%)$ и игольчатыми $(1,0-11,0 \%)$. Содержание кварца без включений достигает максимально $13 \%$, местами он отсутствует. Полупрозрачных зерен $1,0-16,0 \%$, непрозрачных до $1,5 \%$.

По особенностям внутренней структуры кварц базальных отложений венда весьма близок к кварцу мигматизированных метаморфических пород данного региона. Резко увеличивается лишь степень окатанности зерен, указывающая на образование базальных слоев не только путем элювиально-делювиальных процессов, но и переотложением осадочного материала в подвижной водной среде.

Несколько заниженную степень окатанности имеет кварц на сводах локальных положительных структур Ульясте (скв. Ф-189, Ф-194). По другим типоморфным особенностям (включения, погасание) произошло существенное выравнивание признаков и заметных аномалий в отложениях данного района не установлено.

В отложениях молдоваской пачки преобладают неокатанные (в среднем $55,2 \%$ ) и полуокатанные (в среднем $41,5 \%$ ), но встречаются и окатанные $(3,3 \%)$ зерна кварца.

По характеру погасания всегда преобладает кварц с нормальным погасанием (до 96,3\%), зерен с волнистым погасанием встречается в среднем только $3,7 \%$. По признаку включений кварц распределяется так: точечных $76,1 \%$, полупрозрачных до $8,3 \%$, призматических, игольчатых и без включений - 2,5\% каждого. Регенерационные каемки практически отсутствуют.

По сравнению с кварцем оруской пачки ассоциация типоморфных разновидностей кварца в рассматриваемых отложениях более однообразна, региональные особенности не проявляются. По комплексу типоморфных признаков (в частности малое содержание кварца с игольчатыми включениями) кварц молдоваской пачки в общем близок к кварцу метаморфических пород, выходы которых в пределах Алутагузеской структурной зоны и в Южной Финляндии могли служить основным источником сноса для основной - молдоваской пачки гдовской свиты.

В песчанистых отложениях у ускюл аской п ч ки неокатанные и полуокатанные зерна кварца распространяются практически в равных 
количествах (в среднем соответственно 48,6 и 49,2\%), а окатанных лишь $2,2 \%$. Преобладает кварц с нормальным погасанием $(94,6 \%)$, кварц с волнистым погасанием составляет в среднем только $5,1 \%$.

Довольно сходная с предыдущей пачкой картина наблюдается также по включениям кварца: явно преобладает кварц с точечными $(72,0 \%)$, следует кварц с изометрическими включениями $(12,3 \%)$ и полупрозрачный $(7,2 \%)$. В незначительном количестве встречается кварц с призматическими $(2,8 \%)$ и игольчатыми включениями $(2,5 \%)$, а также без включений. Регенерационные каемки отсутствуют.

В целом кварц уускюлаской пачки сходен по типоморфным особенностям с кварцем молдоваской пачки, лишь с той разницей, что количество полуокатанных зерен несколько увеличено за счет уменьшения количества неокатанных.

Породы котлинской с виты аналогичны уускюлаской пачке: неокатанные и полуокатанные зерна кварца встречаются почти в равных количествах (в среднем соответственно 45,5 и 48,5\%), но тенденция к убыванию неокатанных продолжается и количество хорошо окатанных в той же степени увеличивается (в среднем до 6\%). В характере погасания и распределения разновидностей включений в кварце котлинской свиты по сравнению с залегающими ниже отложениями заметных различий не наблюдается. Содержание точечных включений составляет $78 \%$, изометрических - 8,1\%, полупрозрачных и игольчатых $-2,0 \%$, призматических $-1,5 \%$, без включений $-2,7 \%$. Встречены редкие зерна c регенерационной каемкой.

В целом кварц в отложениях котлинской свиты весьма близок к кварцу отложений нижележащих пород.

Для пород воронковской с виты характерна высокая степень зрелости по всей территории республики - резко преобладающим минералом является кварц. Окатанность зерен в нижней части свиты в пределах сиргалаской пачки увеличивается снизу вверх, в кровле пачки появляются частые хорошо окатанные зерна кварца. В песчаниках верхней части свиты (к а н н к а с ко й п а к и) окатанные зерна кварца имеют матовую поверхность. По другим типоморфным особенностям заметных различий между сиргалаской и каннукаской пачками не наблюдается.

По сравнению с отложениями нижезалегающей котлинской свиты количество окатанных, полупрозрачных и с изометрическими включениями зерен заметно возрастает в породах воронковской свиты. В некоторых разрезах Северо-Восточной Әстонии, в частности в районе Ульясте, наблюдается аномально высокое содержание кварца с игольчатыми включениями (до $6 \%$ ), что служит индикаторным признаком для гранитоидов. Не исключается возможность, что во время накопления отложений воронковской свиты одним из источников сноса служил Выборгский массив рапакиви-гранитов, и влияние этого локального источника отражалось на некоторой специфике кварца из его непосредственной близости.

Итак, типоморфные особенности кварца в базальных отложениях осадочного чехла не проявляются в виде четких латеральных и вертикальных ассоциаций, но некоторые общие закономерности и тенденции все-же наблюдаются.

Во-первых, относительная роль зерен кварца с волнистым погасанием существенно меньше в осадочных, чем в кристаллических породах фундамента, что, очевидно, объясняется меньшей механической устойчивостью деформированных зерен. В процессе выветривания и последующего длительного многократного переотложения обломочного материала, видимо, происходило дифференцированное разрушение в первую очередь менее устойчивых зерен с волнистым погасанием. 
Во-вторых, в самых древних и менее обработанных в цикле седиментации отложениях осадочного чехла проявляются некоторые черты унаследованности по типоморфным особенностям кварца непосредственно от нижезалегающих пород фундамента, что объясняется влиянием местных источников первичного осадочного материала на их формирование. В более молодых отложениях венда территориальные различия в типоморфных разновидностях кварца практически не проявляются, их ассоциация характеризуется однородностью по площади и устойчивостью во времени. Сочетание разновидностей этой ассоциации в общем аналогично сочетанию разновидностей кварца в метаморфических породах фундамента.

В-третьих, степень окатанности зерен кварца выражает явную тенденцию к увеличению снизу вверх - последовательное уменьшение количества неокатанных и соответственное увеличение полуокатанных и окатанных зерен. Такая закономерность, по всей вероятности, объясняется возрастающей ролью повторного переотложения сформировавшихся отложений снизу вверх, где источником сноса все в большей мере, видимо, служили отложения более древних вендских толщ.

В заключение необходимо отметить, что изучение типоморфных особенностей кластогенного материала решающей информации по процессам литогенеза осадочних пород, видимо, не дает, однако в сочетании с другими данными существенно расширит возможности литогенетического анализа.

\section{ЛИТЕ Р АТ У Р А}

Ванамб В., Кууспалу T., Утсал K. О минералогической зональности коры выветривания кристаллического фундамента Эстонии // Уч. зап. ТГУ, вып. 359. Тр. по геол. VIII. $1977,71-103$.

Кац М. Я., Симанович И. М. Кварц кристаллических пород // Труды ГИН АН СССР. М., 1974, вып. 259.

Клейн В., Конса М. Распределение акцессорных минералов в метаморфических комплексах нижнего протерозоя Северной Эстонии // Изв. АН ЭССР. Геол. 1986, 35, № $2,47-52$.

Конса М. Типоморфные особенности циркона пород кристаллического фундамента Эстонии // Изв. АН ЭССР. Геол., $1986 a, 35$, № 1, 1-9.

Конса М. Циркон в довендской коре выветривания кристаллических пород Эстонии // Изв. АН ЭССР. Геол., 1986б, 35, № 4, 160-162.

Конса М. Типоморфные особенности циркона в базальных отложеннях осадочного чехла северной Прибалтики // Изв. АН ЭССР. Геол., 1987, 36, № 3, 97-103.

Конса М. И., Вийдинг Х. А. Проблема унаследованности минерального состава терригенных отложений (на примере сравнительного изучения коры выветривания кристаллического фундамента и базальных осадочных пород // Терригенные минералы осадочных пород Прибалтики. Таллин, 1983, 41-48.

Кристаллический фундамент Эстоннн. М., 1983.

Кууспалу T., Ванамб В., Утсал К. О минералогии коры выветривания кристаллического фундамента Әстонии // Уч. зап. Тартуского гос. ун-та. 1971, 286, 52-163.

Лисицына H. А. Древняя кора выветривания западной части Казахского нагорья // Тр. Геол. Ин-та АН СССР. М., 1959, 11.

Менс К., Пиррус Э. К стратиграфической номенклатуре вендских отложений Эстонии // Изв. АН ЭССР. Геол., 1980, 29, № 2, 49-54.

Симанович Н. Н. Кварц песчаных пород // Тр. Геол. Ин-та АН СССР. М., 1978, вып. $314,5-23$.

Blatt, H., Christie, J. M. Undulatory extinction in quartz of igneous and metamorphic rocks and its significance in provenance studies of sedimentary rocks // J. Sed. Petr., 1963, 33, 559-579.

Krynine, P. D. Microscopic morphology of quartz types // Pan. Am. Cong. Mining and Geol. Engineers. Annals of 2nd Com., 1946. 


\section{KVARTSI TUPOMORFSED ISEÄRASUSED EESTI KRISTALSES ALUSKORRAS JA SETTEKOMPLEKSI BASAALKIHTIDES}

Artiklis on iseloomustatud kvartsi tüpomorfismi kristalse aluskorra erinevates kivimitüüpides, kristalse aluskorra murenemiskoorikus ja vendi setendite basaalkihtides. Materjalist nähtub, et kvartsi tüpomorfsed erimid võimaldavad hankida lisainformatsiooni pealiskorra basaalkihtide kujunemise kohta.

\section{Mare KONSA}

\section{TYPOMORPHIC FEATURES OF QUARTZ IN THE CRYSTALLINE BASEMENT AND BASAL LAYERS OF SEDIMENTARY ROCKS OF ESTONIA}

The examination of typomorphic varieties of quartz in the crystalline basement, in pre-Vendian weathering rind of crystalline rocks and basal layers of Vendian rocks of Estonia revealed some additional information about typomorphic variations of quartz. The results of the study show that the typomorphic features of quartz may be of use for elucidating the heredity of the above-lying Vendian clastic material. 